\title{
Factors contributing to the surgical retreatment of mandibular fractures
}

\section{João Gualberto de Cerqueira LuZ ${ }^{(a)}$ \\ Rogerio Bonfante Moraes(a) Ricardo Pimenta D'Ávila ${ }^{(b)}$ Marcos Kazuo Yamamoto ${ }^{(a)}$}

(a) Department of Maxillofacial Surgery, Prosthodontics and Traumatology, School of Dentistry, Universidade de São Paulo - USP, São Paulo, SP, Brazil.

(b) Hospital Municipal Dr. Arthur Ribeiro de Saboya, São Paulo, SP, Brazil.

Declaration of Interests: The authors certify that they have no commercial or associative interest that represents a conflict of interest in connection with the manuscript.

Corresponding Author:

João Gualberto de Cerqueira Luz

E-mail: igcluz@usp.br

Submitted: Sep 20, 2012

Accepted for publication: Jan 21, 2013

Last revision: Feb 05, 2013
Abstract: The purpose of this retrospective study was to evaluate contributing factors in patients requiring surgical retreatment of mandibular fractures. Of all the patients with mandibular fractures who were treated using internal fixation at a trauma hospital over a seven-year period, 20 patients $(4.7 \%)$ required a second surgery and thus composed the "reoperated" group. The control group comprised 42 consecutive patients with mandibular fractures who were treated at the same clinic and who healed without complications. Medical charts were reviewed for gender, age, substance abuse history, dental condition, etiology, location of fracture, degree of fragmentation, fracture exposure, teeth in the fracture line, associated facial fractures, polytrauma, time elapsed between trauma and initial treatment, surgical approach and fixation system. Statistical analyses were performed using the Statistical Package for Social Sciences (SPSS) version 20.0; descriptive statistics and the chi-squared test were used to determine differences between groups. Significant differences in substance abuse $(p=0.006)$, dental condition $(p<0.001)$, location of fracture $(p=0.010)$, degree of fragmentation $(p=0.003)$ and fracture exposure $(p<0.001)$ were found. With regard to age and time elapsed between trauma and initial treatment, older patients $(31.4$ years, $S D=11.1)$ and a delay in fracture repair ( 19.1 days, $S D=18.7)$ were more likely to be associated with reoperation. It was concluded that substance abuse, age, dental condition, location of fracture, degree of fragmentation, fracture exposure and the time between trauma and initial treatment should be considered contributing factors to the occurrence of complications that require surgical retreatment of mandibular fractures.

Descriptors: Mandibular Fractures; Jaw Fixation Techniques; Postoperative Complications; Retrospective Studies.

\section{Introduction}

The ideal method for treating mandibular fractures is rigid or stable internal fixation using plates or miniplates. ${ }^{1,2}$ Rigid or stable fixation, or simply internal fixation, is a more cost-effective treatment than non-rigid methods, in part due to the decreased probability of postoperative complications, ${ }^{2}$ that could necessitate further surgery. The consequences of retreatment include greater patient morbidity, further hospitalization and hospital costs and a longer period of absence from work, which leads to high social costs. ${ }^{3}$ Therefore, all efforts should be made to avoid complications during treatment of mandibular fractures. ${ }^{4}$ 
Infection is a common initial complication following the surgical treatment of mandibular fractures, which, in more severe cases, may progress to osteomyelitis and pseudoarthrosis. ${ }^{4,5}$ Other complications requiring reoperation include the nonunion or abnormal union of bone tissue and soft tissue infection associated with screw loosening or plate exposure. Such complications may require further fixation, exploratory surgery to remove the fixation materials, the removal of bone sequestration and refracture. ${ }^{4,6-8}$

There is no consensus in the literature on the most prevalent factors associated with postoperative complications following the treatment of mandibular fractures. Factors including the location of the fracture, its complexity, the presence of a tooth in the fracture line, teeth with extensive caries, periodontal disease and exposed fractures have been reported by a number of studies. ${ }^{9,10}$ Patient habits such as smoking, alcohol consumption, drug abuse, noncompliance and poor oral hygiene are additional important contributing factors that may lead to a requirement for further surgery. ${ }^{6}$ Moreover, age, gender, preexisting medical status and treatment tactics are considered contributing factors to the occurrence of infection or the abnormal union of mandibular fractures. ${ }^{10,11}$

The purpose of this study was to evaluate possible contributing factors in patients requiring a surgical retreatment of mandibular fractures that were originally treated using internal fixations compared with a sample of patients with mandibular fractures that were not associated with complications but that were treated using the same method.

\section{Methodology}

This study was approved by the local human research ethics committee (process no. 0179.0.162.017-09). A retrospective study was conducted using information from the medical charts of patients treated at the Oral and Maxillofacial Surgery Clinic of the Hospital M. Dr. Arthur R. de Saboya, which is a trauma hospital that provides coverage for the southern area of São Paulo, SP, Brazil. The charts of patients treated between 2002 and 2009 were reviewed for mandibular fractures treated with internal fixation. Of the 364 patients identified, $20(4.7 \%)$ developed postoperative complications and required surgical retreatment (the "reoperated group"). For the purposes of comparison, the control group comprised a randomly selected sample of 42 consecutive cases of mandibular fractures treated with internal fixation at the same clinic and during the same period, but that healed without complications (termed the "uncomplicated" group).

The complications that led to surgical retreatment in the reoperated group were nonunion $150 \%$ of cases), soft tissue infection associated with loosened screws or plate exposure (35\%), osteomyelitis $(10 \%)$ and malunion $(5 \%)$. The procedures performed were new fixation ( $30 \%$ of cases), removal of bone sequestration and new fixation (20\%), surgical exploration and removal of fixation material (35\%), removal of bone sequestration $(10 \%)$ and refracture and fixation $(5 \%)$.

All charts were reviewed and the following data were recorded:

- age;

- gender;

- major health conditions, such as diabetes, human immunodeficiency virus status, anemia and cancer;

- substance abuse history (alcohol, drugs and smoking);

- dental condition (dentate, partially edentulous or completely edentulous); and

- the etiology and location of the fracture.

The fractures were classified based on the degree of fragmentation:

- single,

- multiple or

- comminuted.

Fracture exposure, teeth in the fracture line, other facial fractures and polytrauma were also quantified. The time interval between the trauma and the initial treatment was recorded. Importantly, the routine in the hospital in question comprises outpatient triage with an elective repair of isolated mandibular fractures. Access for surgical reduction (intra-oral 
Table 1 - Patient demographics of each group.

\begin{tabular}{|c|c|c|c|c|c|c|c|}
\hline \multirow{3}{*}{ Factor } & \multicolumn{4}{|c|}{ Group } & \multirow{2}{*}{\multicolumn{2}{|c|}{ Total }} & \multirow{3}{*}{$\mathrm{p}$-value } \\
\hline & \multicolumn{2}{|c|}{ Reoperated } & \multicolumn{2}{|c|}{ Uncomplicated } & & & \\
\hline & $\mathrm{n}$ & $\%$ & $\mathrm{n}$ & $\%$ & $n$ & $\%$ & \\
\hline \multicolumn{8}{|l|}{ Gender } \\
\hline Male & 16 & 80.0 & 39 & 92.9 & 55 & 88.7 & \multirow{3}{*}{$0.135^{\mathrm{ns}}$} \\
\hline Female & 4 & 20.0 & 3 & 7.1 & 7 & 11.3 & \\
\hline Total & 20 & 100 & 42 & 100 & 62 & 100 & \\
\hline \multicolumn{8}{|l|}{ Systemic disease } \\
\hline Present & 2 & 10.0 & 2 & 4.8 & 4 & 6.5 & \multirow{3}{*}{$0.433^{\text {ns }}$} \\
\hline Absent & 18 & 90.0 & 40 & 95.2 & 58 & 93.5 & \\
\hline Total & 20 & 100 & 42 & 100 & 62 & 100 & \\
\hline \multicolumn{8}{|l|}{ Substance abuse } \\
\hline Present & 10 & 50.0 & 7 & 16.7 & 17 & 27.4 & \multirow{3}{*}{$0.006^{*}$} \\
\hline Absent & 10 & 50.0 & 35 & 83.3 & 45 & 72.6 & \\
\hline Total & 20 & 100 & 42 & 100 & 62 & 100 & \\
\hline \multicolumn{8}{|l|}{ Dental condition } \\
\hline Dentate & 3 & 15.0 & 32 & 76.2 & 35 & 56.5 & \multirow{4}{*}{$<0.001^{*}$} \\
\hline Partially edentulous & 15 & 75.0 & 8 & 19.0 & 23 & 37.1 & \\
\hline Edentulous & 2 & 10.0 & 2 & 4.8 & 4 & 6.4 & \\
\hline Total & 20 & 100 & 42 & 100 & 62 & 100 & \\
\hline
\end{tabular}

${ }^{*}$ significant; ${ }^{\text {ns }}$ non-significant.

or extra-oral) and the fixation system used in the initial surgery were recorded. All patients received cefazolin during the postoperative period because this antibiotic is used as standard practice in the hospital in question. No maxillomandibular fixation was used during the postoperative period.

The data were tabulated, and chi-squared tests were used for analyses. All categorical variables were analyzed to determine differences between groups. Confidence intervals were calculated for the quantitative variables (age and time elapsed between the trauma and the initial treatment), and means outside these intervals indicated significant differences between the groups. The level of significance was set to $5 \%(p<0.050)$ for all statistical analyses. The Statistical Package for Social Sciences (SPSS) version 20.0 (IBM Software Group, Chicago, USA) was used for all analyses.

\section{Results}

Most patients in both the reoperated $(80 \%)$ and the uncomplicated $(92.9 \%)$ group were males, with no statistically significant difference between groups $(p=0.135)$. Only a few cases of major systemic disease were noted in the reoperated $(10 \%)$ and uncomplicated $(4.8 \%)$ groups $(p=0.433)$. Half of the patients in the reoperated group (50\%) and $16.7 \%$ of the uncomplicated group reported having abused drugs; this difference was statistically significant ( $p=0.006)$. With regard to dental status, $75 \%$ of the patients in the reoperated group were partially edentulous, whereas dentate patients predominated in the uncomplicated group (76.2\%) $(p<0.001)$. Table 1 shows the patient characteristics of each group.

The predominant etiologies in the reoperated group were aggression (30\%) and motor vehicle accidents $(30 \%)$, followed by gunshot injuries $(25 \%)$. The predominant etiology in the uncomplicated group was motor vehicle accidents (28.6\%), followed by aggression $(26.2 \%)$ and falls $(16.7 \%)$. However, no significant difference in etiology between groups 
Table 2 - Distribution of the cases of mandibular fracture based on etiology and group.

\begin{tabular}{|c|c|c|c|c|c|c|c|}
\hline \multirow{3}{*}{ Etiology } & \multicolumn{4}{|c|}{ Group } & \multirow{2}{*}{\multicolumn{2}{|c|}{ Total }} & \multirow{3}{*}{$p$-value } \\
\hline & \multicolumn{2}{|c|}{ Reoperated } & \multicolumn{2}{|c|}{ Uncomplicated } & & & \\
\hline & $\mathrm{n}$ & $\%$ & $n$ & $\%$ & $\mathrm{n}$ & $\%$ & \\
\hline Aggressions & 6 & 30.0 & 11 & 26.2 & 17 & 27.4 & \multirow{9}{*}{$0.109^{\text {ns }}$} \\
\hline Motor vehicle accidents & 6 & 30.0 & 12 & 28.6 & 18 & 29.0 & \\
\hline Gunshot wounds & 5 & 25.0 & 4 & 9.5 & 9 & 14.5 & \\
\hline Falls & 1 & 5.0 & 7 & 16.7 & 8 & 12.9 & \\
\hline Bicycle & 0 & 0.0 & 5 & 11.9 & 5 & 8.1 & \\
\hline Work & 1 & 5.0 & 0 & 0.0 & 1 & 1.6 & \\
\hline Sports & 0 & 0.0 & 3 & 7.1 & 3 & 4.8 & \\
\hline Not available & 1 & 5.0 & 0 & 0.0 & 1 & 1.6 & \\
\hline Total & 20 & 100 & 42 & 100 & 62 & 100 & \\
\hline
\end{tabular}

ns non-significant.

Table 3 - Distribution of the sites of mandibular fractures based on location and group.

\begin{tabular}{|c|c|c|c|c|c|c|c|}
\hline \multirow{3}{*}{ Location } & \multicolumn{4}{|c|}{ Group } & \multirow{2}{*}{\multicolumn{2}{|c|}{ Total }} & \multirow{3}{*}{$p$-value } \\
\hline & \multicolumn{2}{|c|}{ Reoperated } & \multicolumn{2}{|c|}{ Uncomplicated } & & & \\
\hline & $\mathrm{n}$ & $\%$ & $\mathrm{n}$ & $\%$ & $n$ & $\%$ & \\
\hline Symphysis & 9 & 28.1 & 19 & 26.8 & 28 & 27.2 & \multirow{5}{*}{$0.010^{*}$} \\
\hline Body & 14 & 43.8 & 16 & 22.5 & 30 & 29.1 & \\
\hline Angle & 8 & 25.0 & 14 & 19.7 & 22 & 21.4 & \\
\hline Condyle & 1 & 3.1 & 22 & 31.0 & 23 & 22.3 & \\
\hline Total & 32 & 100 & 71 & 100 & 103 & 100 & \\
\hline
\end{tabular}

*significant.

Table 4 - Mean age (years) and time elapsed between the trauma and the initial treatment (days), with confidence intervals, for each group.

\begin{tabular}{|c|c|c|c|c|c|c|c|}
\hline \multirow{2}{*}{ Factor } & \multirow{2}{*}{ Group } & \multirow{2}{*}{$n$} & \multirow{2}{*}{ Mean } & \multirow{2}{*}{ SD } & \multicolumn{2}{|c|}{$\begin{array}{l}95 \% \text { confidence } \\
\text { interval }\end{array}$} & \multirow{2}{*}{$\begin{array}{c}\text { Difference } \\
\text { between } \\
\text { groups }\end{array}$} \\
\hline & & & & & $\begin{array}{l}\text { Lower } \\
\text { limit }\end{array}$ & $\begin{array}{l}\text { Upper } \\
\text { limit }\end{array}$ & \\
\hline \multirow{2}{*}{ Age } & Reoperated & 20 & 31.4 & 11.1 & 26.5 & 36.2 & \multirow{2}{*}{ Significant } \\
\hline & Uncomplicated & 42 & 26.4 & 7.4 & 24.2 & 28.6 & \\
\hline \multirow{2}{*}{ Time elapsed } & Reoperated & 18 & 19.1 & 18.7 & 10.4 & 27.7 & \multirow{2}{*}{ Significant } \\
\hline & Uncomplicated & 42 & 13.5 & 9.0 & 10.8 & 16.2 & \\
\hline
\end{tabular}

was found ( $p=0.109$ ). Table 2 displays the distribution of mandibular fractures based on etiology. The predominant location of the fracture in the reoperated group was in the mandibular body $(43.8 \%)$, which was followed by the symphysis $(28.1 \%)$ and angle $(25 \%)$, whereas the predominant location in the uncomplicated group was in the condyle (31\%), which was followed by the symphysis $(26.8 \%)$ and body $(22.5 \%)$ ( $p=0.010)$. Table 3 displays the dis- tribution of mandibular fractures based on location. The mean age was 31.4 years (standard deviation $[S D]=11.1)$ in the reoperated group and 26.4 years $(\mathrm{SD}=7.4)$ in the uncomplicated group; this difference was statistically significant. The mean time elapsed between the trauma and the initial treatment was 19.1 days $(S D=18.7)$ in the reoperated group and 13.5 days $(\mathrm{SD}=9.0)$ in the uncomplicated group; this difference was also statistically sig- 
Table 5 - Fracture characteristics and the initial surgical fixation for each group.

\begin{tabular}{|c|c|c|c|c|c|c|c|}
\hline \multirow{3}{*}{ Factor } & \multicolumn{4}{|c|}{ Group } & \multirow{2}{*}{\multicolumn{2}{|c|}{ Total }} & \multirow{3}{*}{$p$-value } \\
\hline & \multicolumn{2}{|c|}{ Reoperated } & \multicolumn{2}{|c|}{ Uncomplicated } & & & \\
\hline & $\mathrm{n}$ & $\%$ & $\mathrm{n}$ & $\%$ & $\mathrm{n}$ & $\%$ & \\
\hline \multicolumn{8}{|c|}{ Degree of fragmentation } \\
\hline Single & 6 & 30.0 & 30 & 71.5 & 36 & 58.1 & \multirow{4}{*}{$0.003^{*}$} \\
\hline Multiple & 7 & 35.0 & 3 & 7.1 & 10 & 16.1 & \\
\hline Comminuted & 7 & 35.0 & 9 & 21.4 & 16 & 25.8 & \\
\hline Total & 20 & 100 & 42 & 100 & 62 & 100 & \\
\hline \multicolumn{8}{|l|}{ Fracture exposure } \\
\hline Present & 16 & 80.0 & 9 & 21.4 & 25 & 40.3 & \multirow{3}{*}{$<0.001^{*}$} \\
\hline Absent & 4 & 20.0 & 33 & 78.6 & 37 & 59.7 & \\
\hline Total & 20 & 100 & 42 & 100 & 62 & 100 & \\
\hline \multicolumn{8}{|c|}{ Teeth in the fracture line } \\
\hline Present & 13 & 65.0 & 22 & 52.4 & 35 & 56.4 & \multirow{3}{*}{$0.349^{\text {ns }}$} \\
\hline Absent & 7 & 35.0 & 20 & 47.6 & 27 & 43.6 & \\
\hline Total & 20 & 100 & 42 & 100 & 62 & 100 & \\
\hline \multicolumn{8}{|c|}{ Associated facial fractures } \\
\hline Present & 4 & 20.0 & 4 & 9.5 & 8 & 12.9 & \multirow{3}{*}{$0.250^{\text {ns }}$} \\
\hline Absent & 16 & 80.0 & 38 & 90.5 & 54 & 87.1 & \\
\hline Total & 20 & 100 & 42 & 100 & 62 & 100 & \\
\hline \multicolumn{8}{|l|}{ Polytrauma } \\
\hline Present & 6 & 30.0 & 7 & 16.7 & 13 & 21.0 & \multirow{3}{*}{$0.228^{\text {ns }}$} \\
\hline Absent & 14 & 70.0 & 35 & 83.3 & 49 & 79.0 & \\
\hline Total & 20 & 100 & 42 & 100 & 62 & 100 & \\
\hline \multicolumn{8}{|l|}{ Surgical approach } \\
\hline Intra-oral & 5 & 25.0 & 19 & 45.2 & 24 & 38.7 & \multirow{3}{*}{$0.126^{\text {ns }}$} \\
\hline Extra-oral & 15 & 75.0 & 23 & 54.8 & 38 & 61.3 & \\
\hline Total & 20 & 100 & 42 & 100 & 62 & 100 & \\
\hline \multicolumn{8}{|c|}{ Initial fixation system } \\
\hline $2.0 \mathrm{~mm}$ & 11 & 55.0 & 22 & 52.4 & 33 & 53.2 & \multirow{3}{*}{$0.847^{n=}$} \\
\hline $2.4 \mathrm{~mm}$ & 9 & 45.0 & 20 & 47.6 & 29 & 46.8 & \\
\hline Total & 20 & 100 & 42 & 100 & 62 & 100 & \\
\hline
\end{tabular}

*significant; ${ }^{\text {ns }}$ non-significant

nificant. Data from 2 cases in the reoperated group were not available. In the reoperated group, many patients who waited a longer time had polytrauma. Table 4 displays the mean age and the time elapsed between the trauma and the initial treatment in both groups.

With regard to the degree of fragmentation, there was a predominance of multiple $(35 \%)$ and comminuted $(35 \%)$ fractures, followed by single
(30\%) fractures in the reoperated group, and a predominance of single $(71.5 \%)$ fractures in the uncomplicated group $(p=0.003)$. Fracture exposure occurred in the majority of cases $(80 \%)$ in the reoperated group and was absent in the majority of cases (78.6\%) in the uncomplicated group $(p<0.001)$. The majority of cases in both the reoperated $(65 \%)$ and uncomplicated $(52.4 \%)$ groups $(p=0.349)$ showed teeth in the fracture line. Some cases of associated 
facial fractures were found in both the reoperated $(20 \%)$ and uncomplicated $(9.5 \%)$ groups $(p=0.250)$. Some polytrauma occurred in the reoperated $(30 \%)$ and uncomplicated $(16.7 \%)$ groups $(p=0.228)$. The most frequent surgical access during the initial surgery was extra-oral in both the reoperated $(75 \%)$ and uncomplicated $(54.8 \%)$ groups $(p=0.126)$. An initial fixation using the $2.0-\mathrm{mm}$ system predominated in both the reoperated $(55 \%)$ and uncomplicated $(52.4 \%)$ groups $(p=0.847)$. Table 5 displays the fracture characteristics and the initial surgical fixation in each group.

\section{Discussion}

This study evaluated factors in patients that may contribute to the surgical retreatment of mandibular fractures that were initially treated using internal fixation compared with mandibular fractures without complications and found significant differences between groups in patient characteristics, fracture characteristics and surgical treatment. Recognizing these contributing factors may help prevent the requirement for retreatment. It has been reported that patient factors contribute more to complications than do iatrogenic factors in the treatment of mandibular fractures. ${ }^{12}$

Of the patient demographics, significant differences between groups were found in terms of substance abuse, age and dental condition. It has been demonstrated previously that alcohol abuse, smoking and drug use are contributing factors to the development of postoperative infection. ${ }^{4,13-16}$ Nicotine reduces vascularization, which is associated with a slower repair process, at bone repair sites. ${ }^{8}$ Patients who smoke and drink alcohol often fail to comply with treatment, which elevates the rate of complications. ${ }^{5}$ In this study, a significant difference in age was found between the groups, with a higher mean age (31.4 years; SD: 11.1 years) in the reoperated group. Age has been associated with the abnormal union of mandibular fractures, which is likely due to a decline in general health. ${ }^{10,11}$ Moreover, a study addressing infection following mandibular fractures showed that older patients were more likely to exhibit this complication. ${ }^{12}$ There was also a predominance of partially edentulous patients in the reoper- ated group. This finding is consistent with a previous study that showed a greater frequency of partially edentulous individuals in a series of mandibular fractures showing nonunion. ${ }^{4}$ The possibility that malocclusion may induce postoperative instability in partially edentulous individuals should be considered, and occlusal analysis should be included in the preoperative evaluation of these patients. ${ }^{17}$

With regard to fracture characteristics, significant differences were found between groups in terms of the location, degree of fragmentation and fracture exposure. There were more cases with complications in the body region in the reoperated group than in the uncomplicated group. This location has been shown to be a frequent site of nonunion that requires symptomatic plate removal.,49 Impaired bone supply due to bone atrophy in partially edentulous patients and mucoperiosteal stripping have both been described to underlie complications in this location. ${ }^{4}$ There was a predominance of comminuted and multiple fractures in the reoperated group. A significant correlation has previously been demonstrated between the development of complications and the degree of fracture fragmentation. ${ }^{9,10,18,19}$ Multiple and comminuted fractures of the mandible can induce stability deficits, which can lead to nonunion. ${ }^{4}$ In such cases, the use of stronger materials for osteosynthesis is suggested to avoid complications. ${ }^{20}$ This finding was demonstrated here by the higher number of multiple or comminuted fractures in the group with complications that required reoperation. Complications in the treatment of mandibular fractures are related more to the severity of the fracture than to the type of treatment employed..$^{18}$ Moreover, there was a predominance of intra-oral exposure in the reoperated group. An exposed fracture presents a great risk of infection, and more rigid systems are indicated in the treatment of such cases. ${ }^{1}$

With regard to the surgical treatment, a significant difference was found between groups in the time elapsed between the trauma and the initial treatment; the elapsed period was longer in the reoperated group. Moreover, the majority of patients in the reoperated group who waited a longer time prior to seeking treatment were cases of polytrauma. 
Early fracture reduction has been associated with a reduced rate of complications, ${ }^{4}$ and delayed medical care has been reported to be a strong predictor of the development of infection. ${ }^{10,18}$ However, there is no robust evidence of the effect of immediate treatment of mandibular fractures on minimizing repair complications compared with later treatment. ${ }^{15,21} \mathrm{~A}$ diverse set of opinions indicate that other factors, such as type of injury, dental status, medical status and adequacy of fixation, may influence these studied complications. ${ }^{4}$ The mean period of time between the trauma and the initial treatment in the uncomplicated group was governed by the routine of the clinic. Although the waiting time was longer, this clinic routine did not cause further issues in the uncomplicated group. Outpatient triage with an elective repair of isolated mandibular fractures has

\section{References}

1. Moraes RB, Landes CA, Luz JGC. Fixation of mandibular fractures with plates or miniplates: prospective study. Minerva Stomatol. 2010 Apr;59(4):159-66.

2. Dodson TB, Pfeffle RC. Cost-effectiveness analysis of open reduction/nonrigid fixation and open reduction/rigid fixation to treat mandibular fractures. Oral Surg Oral Med Oral Pathol Oral Radiol Endod. 1995 Jul;80(1):5-11.

3. Assael LA. Treatment of mandibular angle fractures: plate and screw fixation. J Oral Maxillofac Surg. 1994 Jul;52(7):757-61.

4. Mathog RH, Toma V, Clayman L, Wolf S. Nonunion of the mandible: an analysis of contributing factors. J Oral Maxillofac Surg. 2000 Jul;58(7):746-52.

5. Iizuka T, Lindqvist C, Hallikainen D, Paukku P. Infection after rigid internal fixation of mandibular fractures: a clinical and radiologic study. J Oral Maxillofac Surg. 1991 Jun;49(6):58593.

6. Lamphier J, Ziccardi V, Ruvo A, Janel M. Complications of mandibular fractures in an urban teaching center. J Oral Maxillofac Surg. 2003 Jul;61(7):745-9.

7. Vega LG. Reoperative mandibular trauma: management of posttraumatic mandibular deformities. Oral Maxillofac Surg Clin North Am. 2011 Feb;23(1):47-61.

8. Yamamoto MK, D’Ávila RP, Luz JGC. Evaluation of surgical retreatment of mandibular fractures. J Craniomaxillofac Surg. 2013 Jan;41(1):42-6.

9. Chaushu G, Manor Y, Shoshani Y, Taicher S. Risk factors contributing to symptomatic plate removal in maxillofacial trauma patients. Plast Reconstr Surg. 2000 Feb;105(2):521-5.

10. Malanchuk VO, Kopchak AV. Risk factors for development of infection in patients with mandibular fractures lo- been reported to be more cost-effective than admission with inpatient management. ${ }^{22}$

\section{Conclusion}

This retrospective study evaluated possible contributing factors to additional surgeries in patients treated for mandibular fractures with an initial internal fixation compared with a group of patients without complications. Significant differences between these groups were found in terms of substance abuse, age, dental condition, location of the fracture, the degree of fragmentation, fracture exposure and the time elapsed between the trauma and the initial treatment. Thus, these factors should be considered to contribute to the occurrence of complications that then require surgical retreatment of mandibular fractures.

cated in the tooth-bearing area. J Craniomaxillofac Surg. 2007 Jan;35(1):57-62.

11. Li Z, Zhang W, Li ZB, Li JR. Abnormal union of mandibular fractures: a review of 84 cases. J Oral Maxillofacial Surg. 2006 Aug;64(8):1225-31.

12. Hindawi YH, Oakley GM, Kinsella CR Jr, Cray JJ, Lindsay K, Scifres AM. Antibiotic duration and postoperative infection rates in mandibular fractures. J Craniofac Surg. 2011 Jul;22(4):1375-7.

13. Kirkpatrick D, Gandhi R, Van Sickels JE. Infections associated with locking reconstruction plates: a retrospective review. J Oral Maxillofac Surg. 2003 Apr;61(4):462-6.

14. Serena-Gómez E, Passeri LA. Complications of mandible fractures related to substance abuse. J Oral Maxillofac Surg. 2008 Oct;66(10):2028-34.

15. Hermund NU, Hillerup S, Kofod T, Schwartz O, Andreasen JO. Effect of early or delayed treatment upon healing of mandibular fractures: a systematic literature review. Dent Traumatol. 2008 Feb;24(1):22-6.

16. Mehra P, Van Heukelom E, Cottrell DA. Rigid internal fixation of infected mandibular fractures. J Oral Maxillofac Surg. 2009 May;67(5):1046-51.

17. Libersa P, Roze D, Dumousseau T. Spontaneous mandibular fracture in a partially edentulous patient: case report. J Can Dent Assoc. 2003 Jul-Aug;69(7):428-30.

18. Moreno JC, Fernández A, Ortiz JA, Montalvo JJ. Complication rates associated with different treatments for mandibular fractures. J Oral Maxillofac Surg. 2000 Mar;58(3):273-80. 
19. Ellis E 3rd, Muniz O, Anand K. Treatment considerations for comminuted mandibular fractures. J Oral Maxillofac Surg. 2003 Aug;61(8):861-70.

20. Feller KU, Schneider M, Hlawitschka M, Pfeifer G, Lauer G, Eckelt U. Analysis of complications in fractures of the mandibular angle - a study with finite element computation and evaluation of data of 277 patients. J Craniomaxillofac Surg. 2003 Oct;31(5):290-5.
21. Furr AM, Schweinfurth JM, May WL. Factors associated with long-term complications after repair of mandibular fractures. Laryngoscope 2006 Mar;116(3):427-30.

22. Webb LS, Makhijani S, Khanna M, Burstein MJ, Falk AN, Koumanis DJ, et al. A comparison of outcomes between immediate and delayed repair of mandibular fractures. Can J Plast Surg. 2009 Winter;17(4):124-6. 